\title{
Characteristics of 'Hongrou Taoye', a Grafted Chimera in Sweet Orange and Satsuma Mandarin
}

\author{
Min Zhang ${ }^{1,2 \dagger}$, Zongzhou Xie $^{1 \dagger}$, Xiuxin Deng ${ }^{1 *}$, Shengcai Liao ${ }^{3}$, Wenhua Song ${ }^{3}$, and Yong Tan $^{3}$ \\ ${ }^{1}$ Key Laboratory of Horticultural Plant Biology (Ministry of Education), Huazhong Agricultural University, Wuhan 430070, China \\ ${ }^{2}$ Present address: School of Forestry and Biotechnology, Zhejiang Agricultural \& Forestry University, Lin'an 311300, China \\ ${ }^{3}$ Agricultural Bureau of Zigui County, Yichang 443600, China
}

\begin{abstract}
The synthesis of chimeras is a breeding approach for horticultural crops. In our breeding program, a new diploid citrus chimera, named 'Hongrou Taoye' (Citrus sinensis [L.] Osbeck + Citrus unshiu Marc.), was found arising at the junction where a 'Taoye' sweet orange (C. sinensis) scion was grafted onto Satsuma mandarin (C. unshiu). As an artificial chimera, its fruit traits derived from the L1 cell layer, with juice color and carotenoid complement, in which $\beta$-cryptoxanthin accumulated predominantly, similar to those of Satsuma mandarin. By contrast, traits originating from the L2/L3 cell layer, including pollen, seed, and rind aroma characteristics, were the same as those of 'Taoye' sweet orange (the scion). SSR and cpSSR analyses showed that both nuclear and chloroplast genomes of the chimera were a combination of both donor parents. 'Hongrou Taoye' thus combined the valuable traits of both donor plants, and therefore has good potential in citrus fresh market.
\end{abstract}

Additional key words: carotenoid, citrus, cpSSR, periclinal chimera, SSR

\section{Introduction}

Citrus is the most important fruit crop based on the annual production and consumption. The fresh citrus market favors easy-peeling, seedless, and strong flavor in some areas. During the past 30 years, more than 100 new cultivars of citrus have been released through bud sport selection, crossing and other breeding pipelines in the world (Deng, 2005).

Plants chimera refers to plants whose meristems in stem tip are composed of two or more kinds of cells of different genetic types, out of which the plant develop into a complete one. In other words, two genetically different cells can coordinate to develop an entire plant, even flower and set fruits. Using the grafting technology, Winkler (1907) for the first time synthesized the interspecific chimera of tomato and nightshade. Since then, the synthesis, identification and analysis of plant chimera has been deployed in the research and application in various fields of botany (Marcotrigiano and Bernatyzky, 1995; Szymkowiak and Irish, 1999; Szymkowiak and Sussex, 1992), cytology (Chen et al., 2006), developmental biology (Wang et al., 2011), molecular biology (Bae et al., 2000), the study of the origin and development of tissues and organs (Zhu et al., 2007), and the interactions among cells and the breeding of crops (Zhou et al., 2002).

With the deepening of chimera research, more and more knowledge has been understood, as has promoted the utilization of chimera in plant breeding (Burge et al., 2002). In fact, as early as the 1920 s, researchers have tried to achieve the synthesis of chimera with the purpose of helping plants to resist diseases (Jorgensen, 1927). There were also reports on the application of chimera in anti-insects breeding (Clayberg, 1975; Goffieda et al., 1990). Also, Occurrence

*Comesponding author: xxdeng@mail.hzau.edu.cn

${ }^{\dagger}$ These authors contributed equally to this work.

※ Received 23 September 2014; Revised 23 December 2014; Accepted 6 January 2015. We sincerely thank Dr. Yongyi Cui for reading the manuscript, Ms Lihua Wan for her effort to polish the language, and two anonymous reviewers for comments on the manuscript. This work was supported by the NSFC (30921002; 31000897), and partially by the Zhejiang Provincial Natural Science Foundation of China (Y3090494).

(C) 2015 Korean Society for Horticultural Science 
of graft chimeras spontaneously or artificially in citrus have been reported previously (Kuhara, 1989; Ohtsu and Kuhara, 1994; Shen et al., 1998; Sugawara et al., 2002; Tanaka, 1980; Wu et al., 2004; Zhang et al., 2007).

Recently, a naturally occurring citrus graft chimera named 'Hongrou Taoye' (HT) with deeper red flesh color, has been discovered during screening of citrus bud mutants in Hubei province of China. It arose from the grafting junction of the scion 'Taoye' sweet orange (TSO) and Satsuma mandarin. TSO is a native variety in China with total soluble solids (TSS) content over $12 \%$ when ripening, and selected from the normal sweet orange and denominated in 1965. In this paper, the morphological, cytological, biochemical and molecular characters of this chimera are described.

\section{Materials and Methods}

\section{Plant materials}

The chimera HT was discovered in an orchard in Zigui county of Hubei province during the bud mutation investigation (Fig. 1A). It arose at the junction where a TSO bud was top-worked onto Satsuma mandarin in 1980s. It has been observed later that one branch produced fruits with their pericarp like that of TSO and flesh like that of Satsuma mandarin. Later, the buds from the branch were budded onto trifoliate orange to evaluate the stability of the traits. All the samples including the fruits and leaves were from the budded tress (designated as V1). The V1 individuals of HT and its donor individuals viz. TSO and Satsuma mandarin were maintained at the same orchard.

\section{Morphological analysis}

The length and width of 20 leaves, and the fruit width and height of both the chimera and donor plants were measured. Fruit samples consisted of ten fruits in a tree from three trees.

\section{Scanning electron microscopy (SEM)}

The FAA-fixed anthers were dehydrated using a gradient ethanol series (50, 70, and 95\%) and then degreased by passing them through xylene twice for $20 \mathrm{~min}$ each, followed by critical point drying, mounting on copper stubs, and sputter coating with gold. The samples were examined under a scanning electron microscope (JSM-6390/LV, NTC, Japan) and representative images were obtained.

\section{Flow cytometric analysis}

Ploidy level of HT was determined by flow cytometry according to Zhang et al. (2007). To determine the standard peak of diploid cells (2C DNA), at least 10 leaves were collected respectively from TSO and Satsuma mandarin trees grown in the greenhouse. The standard peak was managed to appear at about channel 50 of relative fluorescent intensity.

\section{HPLC analysis of carotenoids}

Carotenoid pigments were analyzed by RP-HPLC using the modified binary gradient elution procedure originally developed by Lee et al. (2001). Chromatographic analysis was carried out with a Waters (Waters Corporation, Milford, Massachusetts) liquid chromatography system equipped with a model 600E solvent delivery system, a model 2996 photo diode array detection (DAD) system, a model 717 plus autosampler, and an Empower Chromatography Manager (Waters Corporation, Milford, Massachusetts). A C30 Carotenoid column $(150 \times 4.6 \mathrm{~mm}$ I.D., $3 \mu \mathrm{m})$ from YMC (Waters
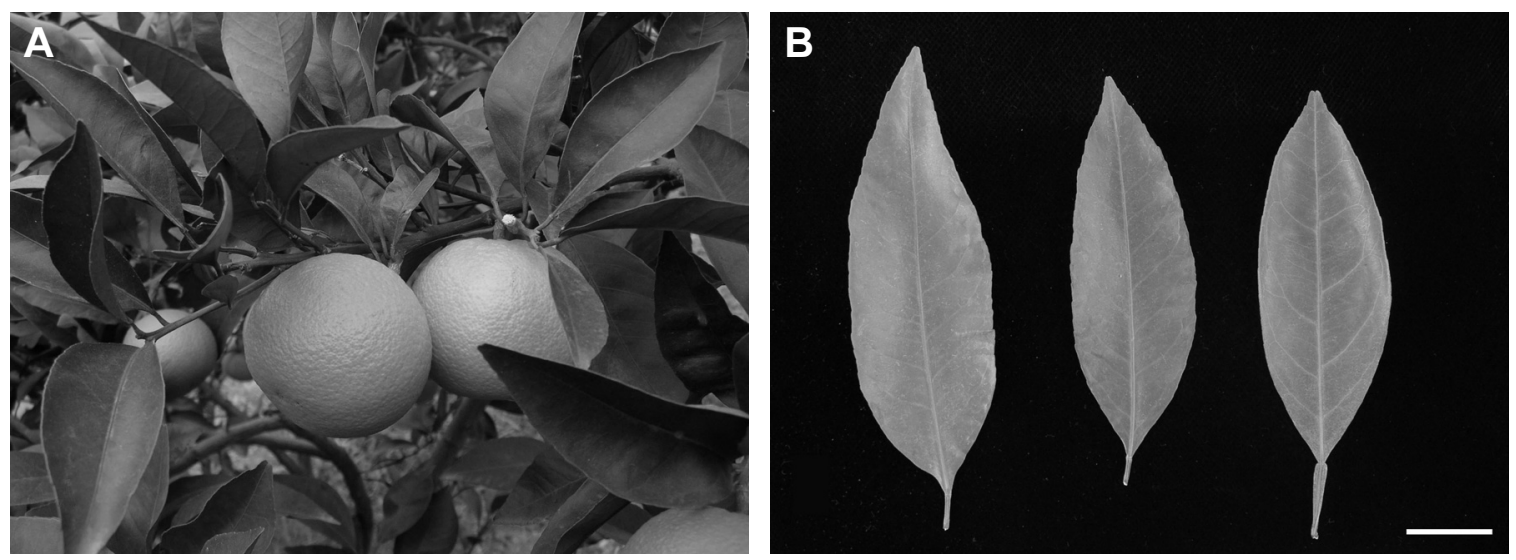

Fig. 1. A: Tree of 'Hongrou Taoye' sweet orange. B: Leaf morphology of 'Hongrou Taoye' sweet orange and its donor plants. From left to right: 'Taoye' sweet orange; 'Hongrou Taoye' sweet orange; Satsuma mandarin. (bars $=1.5 \mathrm{~cm}$ ) 
Corporation, Milford, Massachusetts) was used with $\mathrm{MeOH}$ -MTBE- $\mathrm{H}_{2} \mathrm{O}$ (81: 15: 4, v/v, eluent A) and MeOH-MTBE- $\mathrm{H}_{2} \mathrm{O}$ $(10: 90: 4, v / v$, eluent B) as mobile phases. Analysis was conducted under subdued light to avoid carotenoid degradation during analysis. The Violaxanthin and $\beta$-cryptoxanthin standards were obtained from CaroteNature (CaroteNature, Lupsingen, Switzerland).

\section{DNA extraction and SSR (simple sequence repeats), cpSSR} (chloroplast SSR) analysis

The total DNA of HT and its donor parents were extracted from the leaves by the method according to Cheng et al. (2003a).

Both SSR and cpSSR analyses were conducted according to the procedure of Cheng et al. (2003b, 2005). The PCR products were analyzed in the $6.0 \%(\mathrm{w} / \mathrm{v})$ denatured polyacrylamide gels followed by silver staining according to the protocol of the technical manual on silver sequence DNA staining reagents (Promega, Madison, Wis.). Primers (TAA1, TAA15, TAA27, TAA33, TAA52) used for SSR analysis were based on those of Kijas et al. (1994). CpSSR analysis was performed with primers (SPCC1, SPCC3, SPCC9, SPCC11) synthesized according to the report of Cheng et al. (2005).

\section{Statistical Analysis}

Each treatment of all the experiments was replicated ten times. Statistical analyses were performed with SAS 9.1 (SAS Institute Inc., Cary, NC, USA). Means within a line followed by different letters are significantly different at $p=0.01$ according to LSD test.

\section{Results and Discussion}

\section{Morphology characters of leaf and fruit}

The leaf shape of HT was similar to that of TSO. The shape of the spring leaves was similar to the leaves of peach and their petiole wings were not so obvious. But the leaf width of HT $(4.60 \mathrm{~cm})$ was broader than that of TSO $(3.96 \mathrm{~cm})$. So the leaf index of HT was between its donor parents (Table 1, Fig. 1B). Photographs of fruits of the chimeras and donor parents are shown in Figure 2A. TSO had short spheroid fruits which were $6.79 \mathrm{~cm}$ in diameter and $6.08 \mathrm{~cm}$ in height, and had yellow juice sacs (Fig. 2B). The aroma of its rind was strong. HT had short spheroid fruits with a diameter of $7.21 \mathrm{~cm}$ and a height of $6.16 \mathrm{~cm}$, the aroma of which was similar to that of TSO. But the color of its juice sacs was deep orange, which was the same as that of Satsuma mandarin (Fig. 2B). HT had 11.5 seeds per fruit, which was similar to that of TSO (10.8 seeds per fruit) and different from the seedless Satsuma mandarin (Table 1, Fig. 2B). Interestingly, HT fruits are easy peeling; although not so easy as Satsuma mandarin, they are much easier to peel than TSO.

\section{Morphology of mature pollen using SEM}

The pollens of HT and its donors were observed through scanning electron microscope. The morphology, the size and the ornamentation of exine of HT were similar to those of TSO but different from those of Satsuma mandarin. Mature pollen grains from TSO and HT were spherical and 23-25 $\mu \mathrm{m}$ in diameter. They were characterized by aperture ornamentation and 4-5 shallow colporates. There were

Table 1. Morphological characters of 'Hongrou Taoye' and its donor plants.

\begin{tabular}{lccc}
\hline Characteristics & 'Guoqing No.1' Satsuma mandarin & 'Hongrou Taoye' & 'Taoye' sweet orange \\
\hline Leaf length (cm) & $10.6 \pm 0.89 \mathrm{~b}^{\mathrm{z}}$ & $12.66 \pm 1.93 \mathrm{a}$ & $11.96 \pm 1.00 \mathrm{a}$ \\
Leaf width (cm) & $3.98 \pm 0.44 \mathrm{~b}$ & $4.60 \pm 0.71 \mathrm{a}$ & $3.96 \pm 0.54 \mathrm{~b}$ \\
Leaf index (length/width) & $2.67 \pm 0.25 \mathrm{~b}$ & $2.76 \pm 0.16 \mathrm{ab}$ & $3.05 \pm 0.29 \mathrm{a}$ \\
Fruit width (cm) & $6.48 \pm 0.25 \mathrm{~b}$ & $7.21 \pm 0.16 \mathrm{a}$ & $6.79 \pm 0.22 \mathrm{~b}$ \\
Fruit height (cm) & $5.10 \pm 0.29 \mathrm{~b}$ & $6.16 \pm 0.11 \mathrm{a}$ & $6.08 \pm 0.19 \mathrm{a}$ \\
Fruit size ratio (height/width) & $0.79 \pm 0.04 \mathrm{~b}$ & $0.85 \pm 0.03 \mathrm{a}$ & $0.89 \pm 0.02 \mathrm{a}$ \\
Seed number (per fruit) & $0 \mathrm{~b}$ & $11.5 \pm 5.2 \mathrm{a}$ & $10.8 \pm 4.5 \mathrm{a}$ \\
Shape & Oblate & Short Spheroid & Short Spheroid \\
Color of juice sac & Orange & Orange & Yellow \\
Aroma of rind & Weak & Strong & Strong
\end{tabular}

${ }^{z}$ Means within a line followed by different letters are significantly different at $p=0.01$ according to least-significance difference test. 

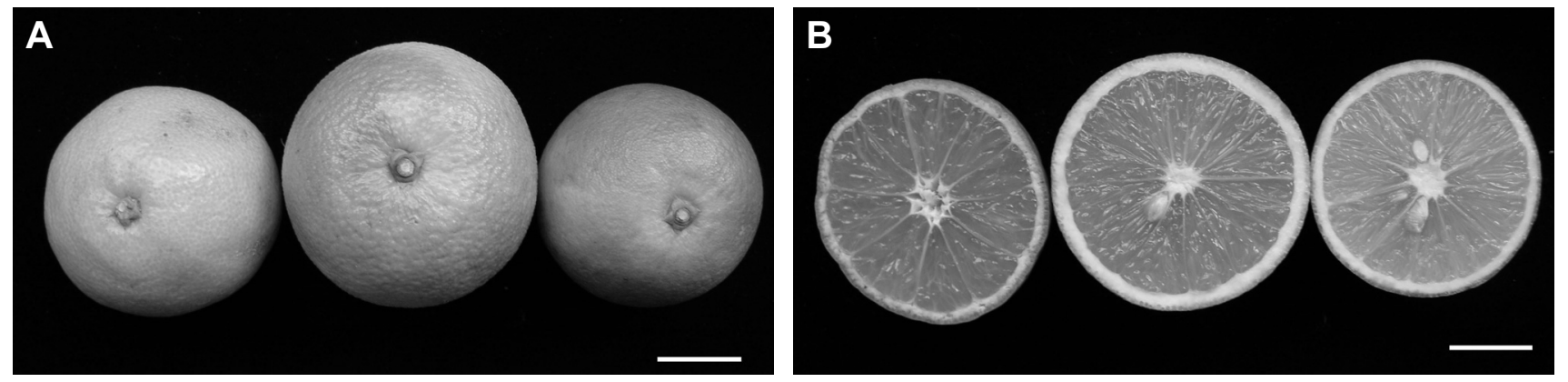

Fig. 2. Fruit morphology of 'Hongrou Taoye' and its donor plants. From left to right: 'Guoqing No.1' Satsuma mandarin; 'Hongrou Taoye'; 'Taoye' sweet orange (bars $=3 \mathrm{~cm}$ )

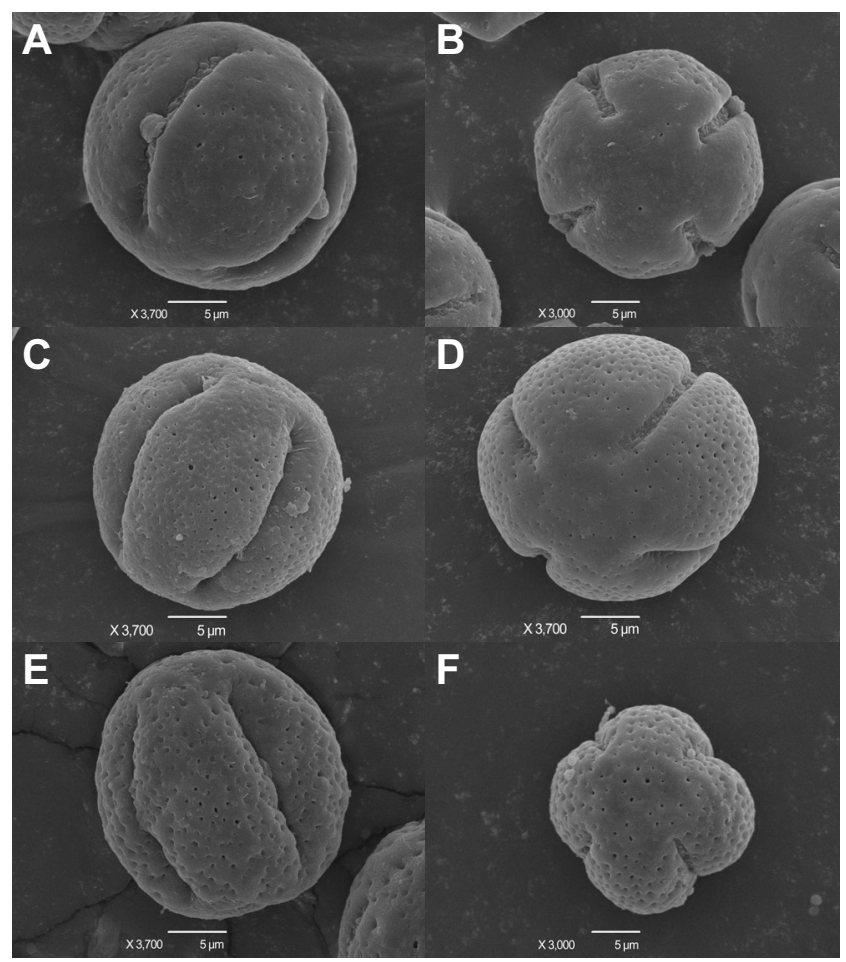

Fig. 3. Pollen morphology of 'Hongrou Taoye' sweet orange and its donors (bars $=5 \mu \mathrm{m}$ ).

A : Pollen of 'Taoye' sweet orange, equatorial view

B : Pollen of 'Taoye' sweet orange, polar view

C : Pollen of 'Hongrou Taoye' sweet orange, equatorial view

D : Pollen of 'Hongrou Taoye' sweet orange, polar view

E : Pollen of 'Guoqing No.1' Satsuma mandarin, equatorial view F : Pollen of 'Guoqing No.1' Satsuma mandarin, polar view

some granules in the colporate (Fig. 3A, B, C, D). Compared with them, mature pollen grains from Satsuma mandarin were ellipse or spherical and $24-26 \mu \mathrm{m}$ in diameter. They possess aperture ornamentation and 4 deep colporates (Fig. 3E, F).

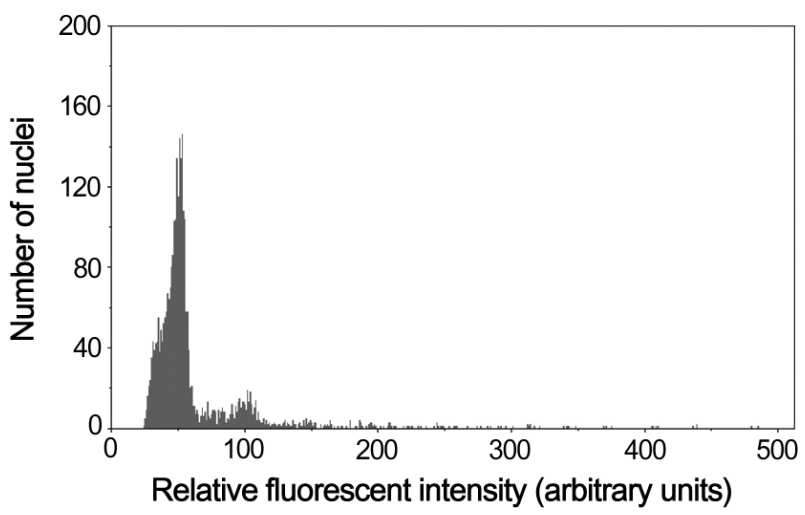

Fig. 4. Ploidy analysis of 'Hongrou Taoye' sweet orange and its donor plants (three samples were run together).

\section{Ploidy determination}

Flow cytometry was used to analyze the ploidy levels of HT and its donor parents. When compared with the diploid control, TSO and Satsuma mandarin, whose fluorescence intensities were present to 50. HT demonstrated the fluorescence intensity similar to the control, indicating its diploid nature (Fig. 4).

\section{Identification of Carotenoids}

By comparing their absorption spectra and retention times with those of purchased authentic standards, mature TSO predominantly accumulated Violaxanthin isomers in the flesh (Fig. 5A). Violaxanthin is a yellowish pigment with the main cis-form in citrus having a visible absorption peaks of 413, 436 and $465 \mathrm{~nm}$, while the pigment with the highest concentration in Satsuma mandarin was $\beta$ -cryptoxanthin. It is an orange color carotenoid with visible absorption peaks of 479, 452 and $429 \mathrm{~nm}$. Results showed that both HT and Satsuma mandarin accumulated $\beta$-cryptoxanthin predominantly in the juice sacs in the mature fruit (Fig. $5 B, C)$. 

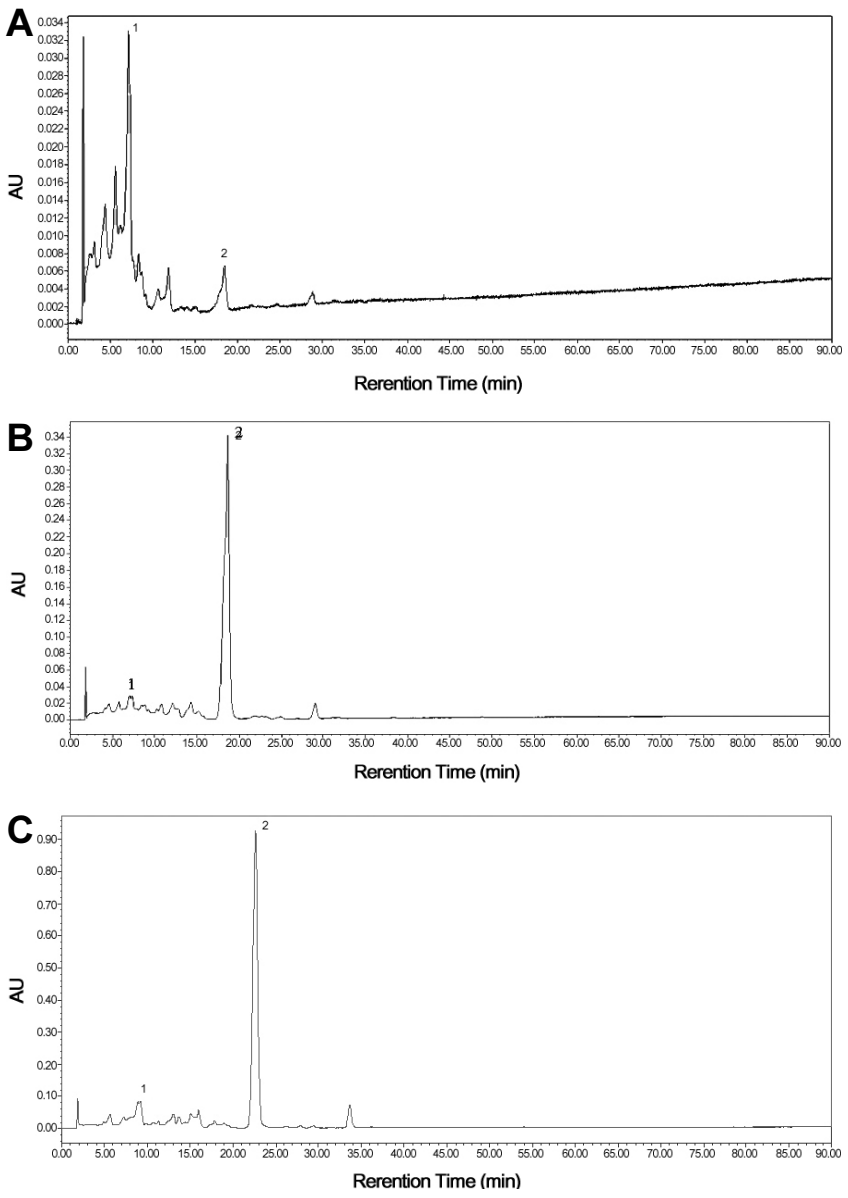

Fig. 5. HPLC chromatogram for carotenoid in the flesh of 'Hongrou Taoye' sweet orange (B) and its donors: 'Taoye' sweet orange (A) and 'Guoqing No.1' Satsuma mandarin (C). (peak 1: cis-Violaxanthin; peak 2: $\beta$-cryptoxanthin; $\mathrm{AU}=$ Absorbance Units)

\section{Characterization of nuclear genome and chloroplast genome}

To determine the nuclear composition, SSR analysis was performed with HT and its two donor parents. One out of the five tested SSR primers, TAA15 revealed polymorphism between $C$. sinensis and $C$. unshiu. The amplified products of this primer showed that the band patterns of HT contained amplified bands from both TSO and Satsuma mandarin (Fig. 6A), which indicated that HT contained nuclear genomes from these two donors. For the chloroplast genome, HT was characterized by using four pairs of cpSSR primers (SPCC1, SPCC3, SPCC9 and SPCC11). The results revealed polymorphism between TSO and Satsuma mandarin. The graft chimera shared the same banding patterns with both TSO and Satsuma mandarin, which demonstrated that the graft chimera contained the chloroplast genomes from both donor parents (Fig. 6B). The above results show that HT
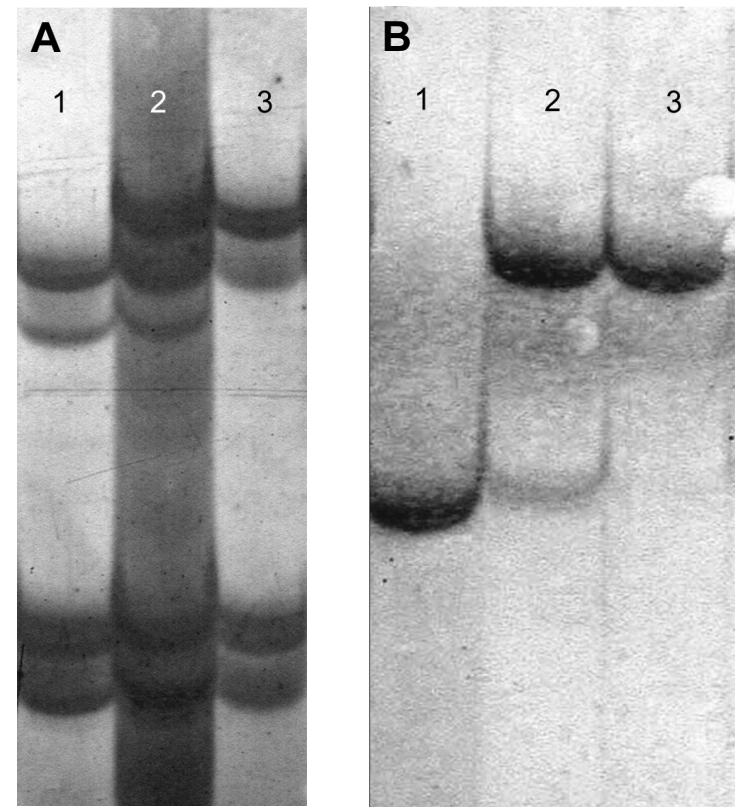

Fig. 6. SSR analysis of 'Hongrou Taoye' and its donor plants. Primer TAA15 for nuclear genome (A), and primer SPCC1 for chloroplast genome (B). Lane 1: 'Guoqing No. 1' Satsuma mandarin; lane 2: 'Hongrou Taoye'; lane 3: 'Taoye' sweet orange.

is a graft generating periclinal chimera that consists of L1 from Satsuma mandarin and L2/L3 from TSO. Characters determined by L1 cell layer, such as juice sacs of the fruit were similar to those of Satsuma mandarin. While other characteristics, including petiole wing, fruit shape, the color and aroma of the rind, pollen, and seed determined by L2 cell layer, were the same as those of TSO. These were consistent with the results that juice sacs were originated from the L1 layer and gametes were usually produced by the L2 layer (Marcotrigiano and Bernatzky 1995; Zhou et al. 2002). In this study, the whole leaves were used to isolate DNA; because L1 cells of an apical meristem give rise to the epidermis of the leaf, and the cells of L2 and L3 give rise to the mesophyll (Frost and Krug 1942; Tilney-Bassett 1986), the SSR and cpSSR analyses showed that the graft chimera contained nucleic and chloroplast genomes from both donor parents.

Intercellular morphogenetic and physiological interactions and cell displacement have been observed in chimeric paints (Szymkowiak and Irish, 1999; Zhou et al. 2002). The observations reported here on leaf index (Table 1), both nuclear (Fig. 6A) and chloroplast (Fig. 6B) genome, and the aroma of flesh in this study indicated that chimeric cells likely were derived from both parental cultivars. Further studies are required to reveal the interaction between cells 
of Satsuma mandarin and 'Taoye' sweet orange in the chimera 'Hongrou Taoye'.

The characteristics of HT have been maintained for several years and the phenotype is agronomic traits stable after vegetative propagation. Its fruit has a flavor and texture with mixture of Satsuma mandarin and TSO. The flesh is orange in color, fine and crisp in texture, and very juicy with strong aroma. The whole fruit has pleasant smell and excellent shelf life as TSO. So, HT combines the valuable traits of both donor parents. It is expected to be a commercially acceptable chimeric cultivar for the citrus industry.

\section{Literature Cited}

Bae, C.H., T. Abe, N. Nagata, N. Fukunishi, T. Matsuyama, T. Nakano, and S. Yoshida. 2000. Characterization of a periclinal chimera variegated tobacco (Nicotiana tabacum L.). Plant Sci. 151:93-101.

Burge, G.K., E.R. Morgan, and J.F. Seelye. 2002. Opportunities for synthetic plant chimeral breeding: past and future. Plant Cell, Tissue Organ Cult. 70:13-21.

Chen, L.P., Y.M. Ge, and X.Y. Zhu. 2006. Artificial synthesis of interspecific chimeras between tuber mustard (Brassica juncea) and cabbage (Brassica oleracea) and cytological analysis. Plant Cell Rep. 25:907-913.

Cheng, Y.J., M. Carmen, H.J. Meng, W.W. Guo, N.G. Tao, and X.X. Deng. 2005. A set of primers for analyzing chloroplast DNA diversity in Citrus and related genera. Tree Physiol. 25:661-672.

Cheng, Y.J., W.W. Guo, and X.X. Deng. 2003b. cpSSR: a new tool to analyze chloroplast genome of Citrus somatic hybrids. Acta Bot. Sin. 45:906-909.

Cheng, Y.J., W.W. Guo, H.L. Yi, X.M. Pang, and X.X. Deng. 2003a. An efficient protocol for genomic DNA extraction from citrus species. Plant Mol. Biol. Rep. 21:177a-177g.

Clayberg, C.D. 1975. Insect-resistance in a graft-induced periclinal chimera of tomato. HortScience 10:13-15.

Deng, X.X. 2005. Advances in worldwide citrus breeding. Acta Hortic. Sin. 32:1140-1146.

Frost, H.B., and C.A. Krug. 1942. Diploid-tetraploid periclinal chimeras as bud variants in citrus. Genetics 27:619-634.

Goffieda, J.C., E.J. Szymkowiak, I.M. Sussex, and M.A. Mutschler. 1990. Chimeric tomato plants show that aphid resistance and triacylglucose production are epidermal autonomous characters. Plant Cell 2:643-649.

Jorgensen, C. A. 1927. A periclinal tomato-potato chimera. Hereditas 10:293-301

Kijas, J.M., J.C. Fowler, C.A. Garbett, and M.R. Thomas. 1994. Enrichment of microsatellites from the citrus genome using biotinylated oligonucleotide sequences bound to streptavidincoated magnetic particles. Biotechniques 16:657-662

Kuhara, S. 1989. Artificial production of citrus periclinal chimera and disease resistance of these plants. Plant Protection (Shokubutsu Bochi) 43:25-29.

Lee, H.S., W.S. Castle, and G.A. Coates. 2001. High-performance liquid chromatography for the characterization of carotenoids in the new sweet orange (Early gold) grown in Florida, USA. J. Chromatogr., A 913:371-377.

Marcotrigiano, M., and R. Bernatzky. 1995. Arrangement of cell layers in the shoot apical meristems of periclinal chimeras influences cell fate. Plant J. 7:193-202.

Ohtsu, Y., and S. Kuhara. 1994. Periclinal chimera of citrus resistant to citrus canker and citrus tristeza virus: Chimerism and composition of fruit tissue in the synthetic periclinal chimeras 'FN-1' and 'FN-3'. Annu. Phytopathol. Soc. Jpn. 60:20-26.

Shen, D.X., Y.Y. Wang, and L.G. Chen. 1998. Citrus genetics and breeding. Scientific Publishers, Beijing, China (in Chinese).

Sugawara, K., T. Wakizuka, A. Oowada, T. Moriguchi, and M. Omura. 2002. Histogenic identification by RAPD analysis of leaves and fruit of newly synthesized chimeric Citrus. J. Am. Soc. Hortic. Sci. 127:104-107.

Szymkowiak, E., and E. Irish. 1999. Interactions between jointless and wild-type tomato tissues during development of the pedicel abscission zone and the inflorescence meristem. Plant Cell 11:159-176.

Szymkowiak, E., and I. Sussex. 1992. The internal meristem layer (L3) determines floral meristem size and carpel number in tomato periclinal chimeras. Plant Cell 4:1089-1100.

Tanaka, Y. 1980. An iconograph of Japanese citrus fruits: A monographic study of species and varieties of citrus fruits grown in Japan. Yokendo Co., Tokyo, Japan.

Tilney-Bassett, R.A.E. 1986. Plant chimeras. Edward Arnold Publishers, London, UK.

Wang, Y., Q. Cheng, X.Y. Zhu, L.P. Chen. 2011. Studies on reproductive characteristics of an interspecific chimera between Brassica juncea and Brassica oleracea. Plant Cell, Tissue Organ Cult. 104:209-215.

Winkler, H. 1907. Description of $S$. nigrolycopersicum and method of obtaining graft-hybrids. Ber eut Bot. Ges. 25:568-576.

Wu, H.M., B.M. Lin, Z.X. Lai, L.X. Lu, G.F. Lin, D.M. Pan, and J.F. Yang. 2004. An intergeneric grafting chimera name: +Citroponcirus 'Hormish'. J. Trop. Subtrop. Bot. 12:177-181 (in Chinese).

Zhang, M., X.X. Deng, C.P. Qin, C.L. Chen, H.Y. Zhang, Q. Liu, Z.Y. Hu, L.L. Guo, W.H. Song, Y. Tan, and S.C. Liao. 2007. Characterization of a new natural periclinal navel-satsuma chimera of citrus: 'Zaohong' navel orange. J. Am. Soc. Hortic. Sci. 132:374-380.

Zhou, J.M., Y. Hirata, I.S. Nou, H. Shiotani, and T. Ito. 2002. Interactions between different genotypic tissues in citrus graft chimeras. Euphytica 126:355-364.

Zhu, X.Y., M. Zhao, S. Ma, Y.M. Ge, M.F. Zhang, and L.P. Chen. 2007. Induction and origin of adventitious shoots from chimeras of Brassica juncea and Brassica oleracea. Plant Cell Rep. 26:1727-1732. 